\title{
Kendali Alat Pelontar Bola Tenis Lapangan Berbasis Mikrokontroler
}

\author{
Gusnita Parmitasari ${ }^{1}$, Sukardi ${ }^{2}$ \\ 1.2 Universitas Negeri Padang \\ Jl. Prof. Dr. Hamka Air Tawar, Padang \\ gusnitaparmitasari@gmail.com ${ }^{1}$,Sukardiunp@gmail.com ${ }^{2}$
}

\begin{abstract}
The problem that often occurs is that the training process given by the trainer only focuses on giving the ball that is directed manually, so that the trainer does not focus too much on improving the skills of his students. This final project aims to develop a tennis ball throwing device in order to provide effectiveness and efficiency in tennis practice. The manufacture of this tool consists of hardware which includes Arduino mega2560, DC motor, stepper motor, BTS7960 motor driver, A4988 stepper motor driver, voltage sensor, push button, potentiometer, switch, LCD 16X2 and I2C and the software used is the Arduino IDE. . The results of the tennis ball throwing device are that it can throw the ball according to the initial design and all components can work according to the initial design. Suggestions in making this tool consist of the use of a tennis ball thrower and its further development. To use a tennis ball throwing device, it is suggested that it can be used as an alternative to improve the skills of students in tennis practice. For further development, it is hoped that the tennis ball throwing device can be used according to technological developments.
\end{abstract}

Keywords - Tennis, ball, racket, development, Arduino Mega 2560, Motor DC, Motor Stepper.

\begin{abstract}
Abstrak - Permasalahan yang sering terjadi yaitu proses latihan yang diberikan oleh pelatih hanya berfokus pada pemberian bola yang diarahkan secara manual, sehingga perlatih tersebut tidak terlalu fokus dalam perbaikan skill anak didiknya. Tugas Akhir ini bertujuan untuk mengembangkan sebuah alat pelontar bola tenis guna memberikan keefektifan serta efisiensi dalam latihan tenis. Pembuatan alat ini terdiri dari perangkat keras (hardware) yang meliputi arduino mega2560, Motor DC, motor stepper, driver motor BTS7960, driver motor stepper A4988, sensor tegangan, push button, potensiometer, switch, LCD 16X2 dan I2C serta perangkat lunak yang digunakan yaitu Arduino IDE. Adapun hasil dari alat pelontar bola tenis adalah dapat melontarkan bola sesuai dengan perancangan awal dan semua komponen dapat bekerja sesuai dengan rancangan awal. Saran dalam pembuatan alat ini terdiri dari pemanfaatan alat pelontar bola tenis dan pengembangan yang lebih lanjut. Untuk pemanfaatan alat pelontar bola tenis, disarankan dapat dijadikan sebagai salah satu alternatif untuk meningkatkan skill anak didik dalam latihan tenis. Untuk pengembangan yang lebih lanjut, diharapkan alat pelontar bola tenis dapat disesuikan seiring perkembangan teknologi.
\end{abstract}

Kata kunci-Tennis, ball, racket, pengembangan, Arduino Mega 2560, Motor DC, Motor Stepper

\section{Pendahuluan}

Tenis lapangan adalah sebuah permainan yang dimainkan diatas lapangan persegi panjang dengan menggunakan bola dan raket. Untuk memenangkan pertandingan tenis adalah dengan cara bola tidak mati di daerah sendiri, dengan kata lain, selalu memukul bola ke daerah lawan. Seorang atlet akan lebih mudah memenangkan pertandingan apabila ia mempunyai dan menguasai semua jenis pukulan atau teknik dalam permainan tenis seperti mengendalikan bola dengan raket tenis, pukulan tenis dasar dan pukulan teknik lanjutan merupakan sebuah tahapan proses dalam latihan tenis.

Banyak jenis pukulan dalam bermain tenis. Oleh karena itu, agar menunjang atlet dalam berlatih, pelatih harus menyusun sebuah program latihan agar altet dapat memahami serta merealisasikan teknik dasar dalam permainan tenis dengan baik dan benar serta dapat menunjang prestasi atlet. Hal tersebut dilakukan agar target yang direncanakan akan terwujud dengan baik serta meningkatkan kemampuan dalam bermain tenis lapangan dengan menerapkan latihan ball feeling[1]. Latihannya biasa dilakukan dengan cara menimangnimang bola dengan cara dipantul menggunakan raket kebawah atau keatas[2].

Tujuan pembuatan alat ini dilakukan agar atlet yang berdomisili di Kota Padang khhususnya atlet PTL UNP bisa termotivasi untuk latihan serta pelatih dapat mengarahkan atlet tersebut dalam bermain tenis dengan baik dan benar. Proses latihan yang diberikan oleh pelatih hanya berfokus pada pemberian bola yang diarahkan secara manual (feeding), sehingga pelatih tersebut tidak terlalu fokus dalam perbaikan skiil anak didiknya[3].

Alat pelontar bola tenis adalah suatu alat yang akan membantu pelatih yang terbuat dari rangkaian alat-alat elektronik dan besi-besi yang dirakit sehingga menjadi sebuah alat yang sudah dirancang. Alat pelontar bola tenis sendiri masih sangat sulit untuk kita jumpai di daerah 
Sumatera terutama di Sumatera Barat, karena pelatih di Sumatera Barat terbiasa menggunakan sistem manual yaitu dengan mendorong bola satu persatu yang akan merepotkan dan akan sulit mengevaluasi gerakan pada atlet. Akan kurang efektif pada latihan yang berjalan dan pemborosan waktu jika atlet yang dilatih banyak tanpa adanya alat tambahan dalam latihan.

Dengan demikian, pelontar bola tenis (feeding) diyakini dapat mengatasi masalah tersebut. Agar pelatih dapat memberikan feedback dalam meningkatkan keterampilan atlet tersebut dalam memukul bola.

\section{METODE}

Dalam pembuatan Tugas Akhir ini ada beberapa komponen pendukung yang digunakan. Kemudian dilakukan perancangan software meliputi Arduino IDE dan perancangan hardwawre yang meliputi perancangan mekanik dan perancangan elektronik,

1) Motor DC [4]

Motor DC (direct current) memerlukan suplai tegangan yang searah pada kumparan medan untuk diubah menjadi energi mekanik. Dalam motor DC terdapat dua kumparan yaitu kumparan medan yang berfungsi untuk mengahsilkan medan magnet dan kumparan jangkar yang berfungsi sebagai tempat terbentuknya gaya gerak listrik (ggl E). Jika arus dalam kumparan jangkar berinteraksi dengan medan magnet, akan timbul torsi (T) yang akan memutar motor.

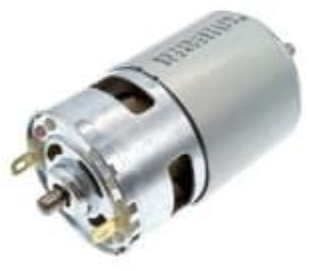

Gambar 1. Motor DC

2) Arduino Mega2560

Arduino Mega 2560 adalah pengendali mikro single board berbasis mikrokontroler pada ATMega2560 yang bersifat open source. Arduino menggunakan bahasa $\mathrm{C}$ yang disederhanakan dengan bantuan pustaka-pustaka (libraries) arduino. Arduino juga menyederhanakan proses bekerja dengan mikrokontroler[5].

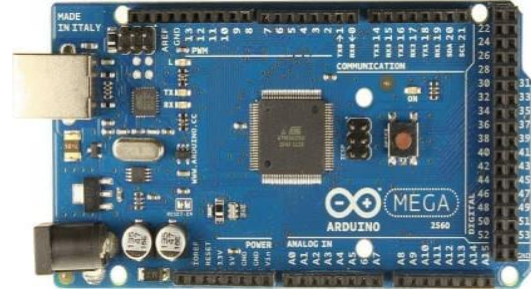

Gambar 2. Arduino Mega2560

3) Motor Stepper

Motor stepper adalah motor listrik yang dikendalikan dengan pulsa-pulsa digital, bukan dengan memberikan tegangan terus-menerus. Deretan pulsa diterjemahkan menjadi putaran shaft, dimana setiap putaran putaran membutuhkan jumlah pulsa yang ditentukan[6].

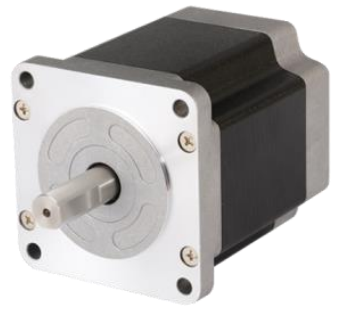

Gambar 3. Motor Stepper

4) Driver Motor BTS7960

Pada driver motor DC ini dapa mengeluarkan arus hingga 43A, dengan memiliki fungsi PWM. Tegangan sumber Dc yang dapat diberikan antara 5.5V27VDC, sedangkan tegangan input level antara 3.3V-\%VDC, driver motor ini menggunakan rangkaian full $\mathrm{H}-$ Bridge dengan IC BTS7960 dengan perlindunga saat terjadi panas dan arus berlebihan[7].

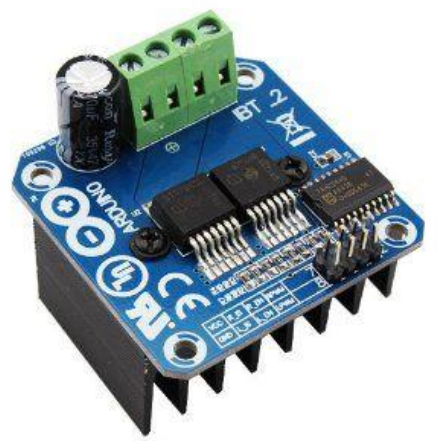

Gambar 4. Driver motor BTS7960

5) A4988 Driver Motor Stepper

A4988 driver motor stepper adalah breakout microsteping allegro yang mudah digunakan untuk driver motor stepper bipolar A4988 dan merupakan pengganti drop-ing untuk carrier driver. 


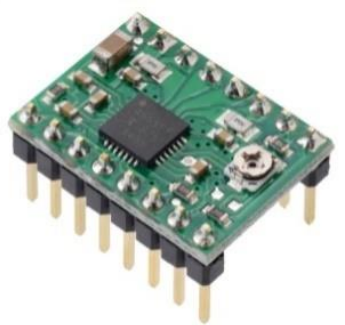

Gambar 5. A4988 Driver Motor Stepper

6) Sensor Tegangan

Sensor tegangan ini digunakan untuk mengukur tegangan AC atau DC. Prinsip kerja sensor tegangan ini didasarkan pada prinsip penekanan resistansi, dan dapat membuat tegangan input berkurang 5 kali dari tegangan asli.

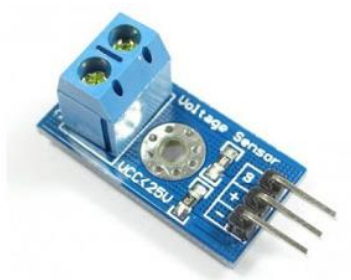

Gambar 7. Sensor Tegangan

7) Liquid Crystal Display 16X2

Serial LCD 16X2 digunakan untuk menghemat pengguanaan pin pada LCD, apabila tidak menggunakan serial maka harus menggunakan lima pin digital. Ketika menggunakan serial LCD hanya mengguanakan pin sda dan scl[8].

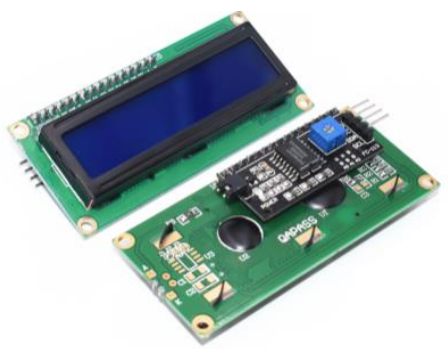

Gambar 8. Liquid Crystal Display 16X2

8) Baterai Lithium Polymer (Li-Po)

Baterai lipo tidak menggunakan cairan sebagai elektrolit melainkan menggunakan elektrolit kering yang berbentuk seperti lapisan plastic film tipis. Lapisan ini disusun diantara anoda dan katoda yang mengakibatkan pertukaran ion[9].

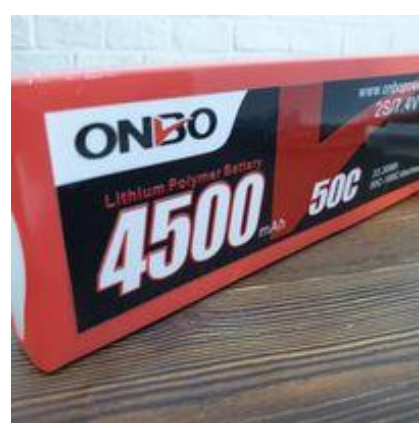

Gambar 9. Baterai Lithium Polymer (Li-Po)

\section{A. Blok Diagram}

Pada pembuatan tugas akhir ini, diperlukannya sebuah diagram blok. Diagram blok itu sendiri yaitu sebuah pernyataan pada rangkaian yang menghubungkan satu rangkaian dengan rnagkaian lainnya, antara masukan dan keluarna dari suatu sistem. Berikut merupakan diagram blok dari Kendali Alat Pelontar Bola Tenis Lapangan Berbasis Mikrokontroler.

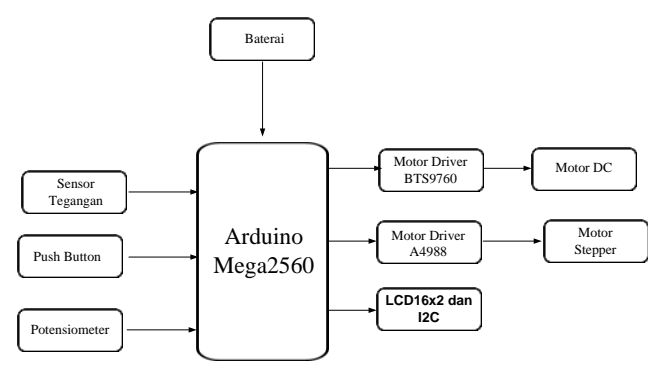

Gambar 10. Diagram Blok Sistem Keseluruhan

Penjelasan tentang gambar 10 blok diagram diatas :

1. Baterai digunakan untuk sumber kelistrikan pada motor dan seluruh komponen yang digunakan.

2. Arus sensor ACS712 digunakan untuk pendeteksi besar kecilnya arus listrik yang masuk pada motor DC.

3. Sensor Tegangan digunakan untuk membaca nilai tegangan pada motor DC.

4. Motor DC penggerak roller agar roller berputar dengan arah yang diinputkan dari driver motor.

5. Driver motor BTS7960 digunakan untuk mengatur sinyal input dari mikrokontroler dan mengatur motor DC.

6. Driver motor stepper A4988 digunakan untuk mengendalikan kecepatan pada motor stepper.

7. Motor stepper digunakan untuk mengarahkan bola sesuai kebutuhan serta pengaturan bola yang masuk pada pipa penyaluran bola tenis.

\section{B. Cara Kerja Alat}

Pada pembuatan Tugas Akhir ini terdapat sebuah proses kerja atau alur kerja yang bersisikan sebuah algoritma dan langkah-langkah yang akan ditampilkan dalam bentuk diagaram berbentuk sebuah flowchart. 
Berikut merupakan flowchart atau diagram alir dari Alat Pelontar Bola Tenis Lapangan Berbasisi Mikrokontroler.

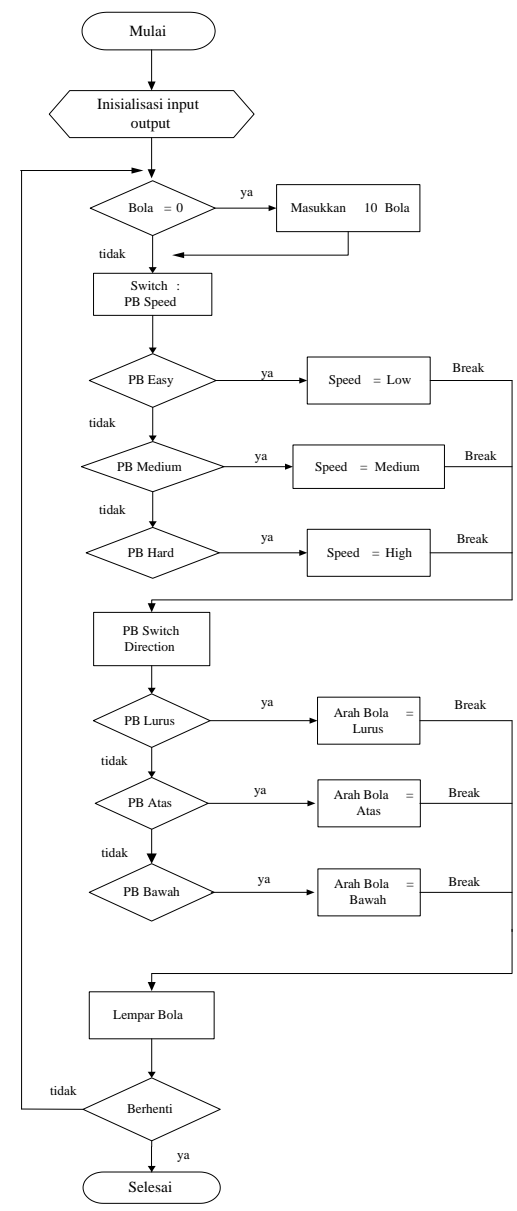

Gambar 11.Diagram Alir Alat Pelontar Bola Tenis

\section{Perancangan Hardware}

Pada ugas Akhir ini, diperlukan sebuah perancangan mekanik yang bertujuan untuk menentukan tata letak dari alat yang dibuat. Perancangan mekanik pada alat ini dibuat berbentuk box yang terbuat dari bahan besi hollow, akrillik serta wadah yang digunakan untuk meletakan bola yang telah tersusun dengan desain yang telah di rancang. Perancangan mekanik yang telah dibuat terpapar pada gambar berikut.

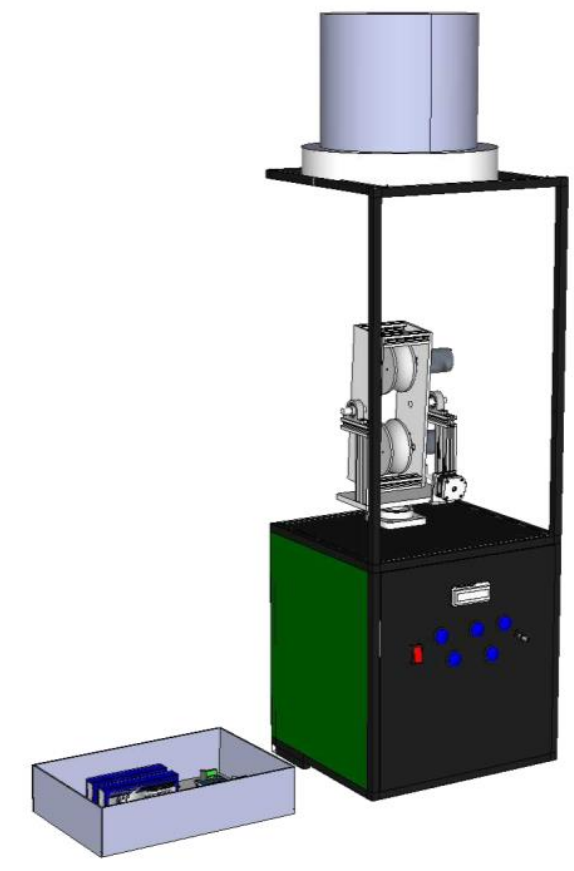

Gambar 12. Perancangan Mekanik Alat Pelontar Bola Tenis

\section{Perancangan Rangkaian Elektronika Keseluruhan}

Pada rangkaian elektronika keseluruhan, terdapat semua komponen yang digunakan diantaranya, rangkaian baterai sebagai sumber arus, rangkaian driver motor BTS7960 yang terhubung dengan motor DC, rangkaian driver motor dtepper A4988 yang terhubung dengan motor stepper dan kapasitor, sensor arus ACS712, sensor tegangan, LCD dan potensiometer yang telah terhubung dengan rangkaian mikrokontroler Arduino mega2560 yang terdapat dibawah ini.

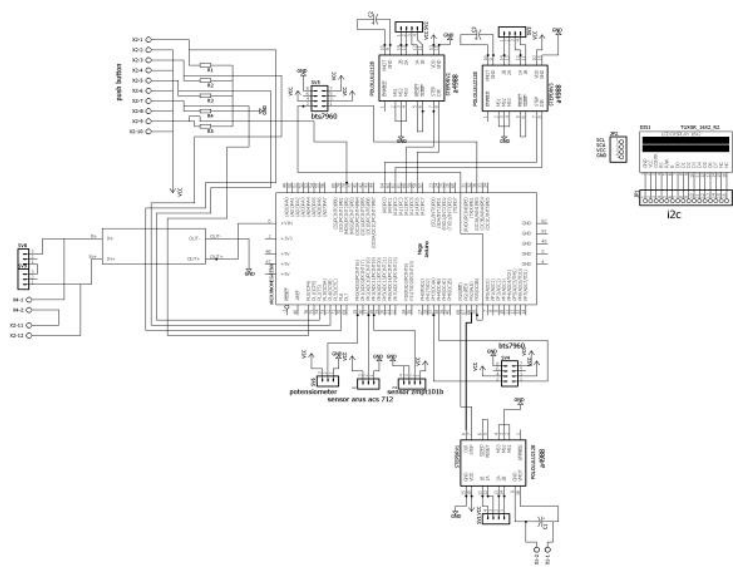

Gambar 12. Skematik Keseluruhan 


\section{HASIL DAN PEMBAHASAN}

Pada bagian hasil dan pembahasan, akan dipaparkan hasil dari pengujian sebuah hardware dan software terhadap kinerja alat pelontar bola tenis. Adapun tujuan pengujian yaitu dapat mengetahui kinerja alat sesuai dengan rancangan awal sehingga didapatkan hasil dan perbandingan dari apa yang direncanakan sebelumnya. Adapun pengujian kendali alat pelontar bola tenis meliputi pengatur kecepatan keluaran bola, pengujian arah keluaran bola serta pengujian jumlah keluaran bola.

\section{Berikut Merupakan Hasil Dari Pengujian Hardware (Perangkat Keras)}

1) Pengujian Pengaturan Kecepatan Keluaran Bola Pengujian pengatur kecepatan keluaran bola dilakukan dengan mengatur kecepatan motor DC menggunakan potensiometer yang telah di program untuk mengaktifkannya. Adapun hasil dari pengujian kecepatan keluaran bola yaitu :

\begin{tabular}{|c|c|c|c|}
\hline No. & $\begin{array}{c}\text { Duty Cycle } \\
(\%)\end{array}$ & $\begin{array}{c}\text { Tegangan } \\
(\mathrm{V})\end{array}$ & RPM \\
\hline 1 & 25 & 2,76 & 3945,4 \\
\hline 2 & 50 & 5,81 & 4189,1 \\
\hline 3 & 75 & 10,82 & 9978,5 \\
\hline 4 & 100 & 13,64 & 12.671 \\
\hline
\end{tabular}

Adapun hasil analisanya yaitu untuk mengatur kecepatan motor DC menggunakan Pulse Width Modulation (PWM) atau modulasi lebar pulsa, yang merupakan sinyal digital berupa gelombang kotak (square wave) dimana duty cycle dari gelombang kotak tersebut dapat diatur sesuai dengan kebutuhan sistem[10]. Dapat dilihat dari tabel diatas bahwa adanya kenaikan tegangan maka kecepatan motor juga akan bertambah, sehingga akan menghasilkan lontaran bola yang diharapkan.

Pada alat pelontar bola tenis, penulis hanya menggunakan 4 kondisi Duty Cycle yaitu 25\%, 50\%, $75 \%, 100 \%$. Nilai PWM yang terdapat pada alat pelontar bola tenis dihitung berdasarkan Duty Cycle yang telah ditetapkan pada alat pelontar bola tenis. Resolusinya yaitu 8 bit dengan rentang nilai sebesar 0-255 (256). Berikut merupakan perhitungan duty cycle yang dirubah dalam bentuk PWM.

1. Duty Cycle untuk $25 \%$

PWM $=$ Duty Cycle $*$ Resolusi PWM

$$
=25 \% * 255
$$$$
=63.75
$$

2. Duty Cycle untuk $50 \%$

PWM $=$ Duty Cycle ${ }^{*}$ Resolusi PWM

$$
=50 \% * 255
$$$$
=127,5
$$

3. Duty Cycle untuk $75 \%$

PWM $=$ Duty Cycle $*$ Resolusi PWM

$$
=25 \% * 255
$$

$=191,25$
4. Duty Cycle untuk $100 \%$

PWM $=$ Duty Cycle $*$ Resolusi PWM

$$
=100 \% * 255
$$$$
=255
$$

2) Pengujian Arah Keluaran Bola

Pengujian untuk arah keluaran bola menggunakan rangkaian driver motor stepper A4988 yang disambungkan dengan motor stepper dapat dikombinasikan pada mikrokontroler dengan program sederhana.

Adapaun hasil dari pengujian yaitu untuk arah keluaran bola penulis menerapkan 2 arah yaitu atas dan bawah. Jarak yang digunakan pada saat pengujian yaitu $6,4 \mathrm{~m}$ dari depan net.

3) Pengujian Jumlah Keluaran Bola

Pengujian yang dilakukan untuk menentukan jumlah keluaran bola dengan memasukkan program pada arduino mega2560. Dari pengujian yang telah di lakukan bahwa rangkaian driver motor stepper A4988 bekerja dengan baik sehingga dapat digunakan.

Adapun hasil pengujian pada jumlah keluaran bola yaitu motor stepper digunakan untuk pengatur jumlah bola yang keluar. Jika rotary yang terhubung dengan motor stepper berputar pada setiap 15 detik, maka bola akan jatuh dan roller pada pelontar bola tenis akan melontarkan bola sesuai dengan program yang telah dibuat.

\section{PEnUtur}

Berdasarkan hasil pengujian dan analisa hardware, software pada Tugas Akhir ini dapat disimpulkan bahwa kendali alat pelontar bola tenis lapangan memberikan efektifitas pelatih dalam proses melatih. Alat pelontar bola tenis dapat membantu pelatih dalam berlatih. Saran untuk pelontar bola tenis yaitu bahan dan komponen elektrikal yang dibutuhkan perlu dipersiapkan dengan matang karena sulitnya menemukan bahan dan komponen elektrikal yang dibutuhkan. Pemanfaatan alat pelontar bola tenis dan pengembangan alat pelontar bola tenis yaitu pelatih dapat memanfaatkan alat ini untuk melatih skill peserta didik dalam latihan tenis serta pada bagian pengembangan yang lebih lanjut diharapkan alat pelontar bola tenis dapat dikembangkan seiring perkembangan teknologi.

\section{REFERENSI}

[1] A. N. Kurniawan, "Pengembangan Model Latihan Ball Feeling Melalui Video Untuk Meningkatkan Teknik," pp. 6-15, 2005.

Raibowo, S., Adi, S., \& Hariadi, I. (2020). Efektivitas dan Uji Kelayakan Bahan Ajar Tenis Lapangan Berbasis Multimedia Interaktif. Jurnal Pendidikan: Teori, Penelitian, dan Pengembangan, 5(7), 944-952. 
[3] F. Pendidikan, U. P. Indonesia, J. Setiabudhi, and N. Bandung, "Pengembangan Teknologi Pelontar Bola," vol. 02, no. 02, pp. 18-24, 2017

[4] Gottlieb, I. (1997). Practical electric motor handbook. Elsevier.

[5] Kadir, A. (2013). Panduan Praktis Mempelajari Aplikasi Mikrokontroler dan Pemrogramannya. Gramedia, Jakarta.

[6] Kalatiku, P. P., \& Joefrie, Y. Y. (2015). Pemrograman Motor Stepper Dengan Menggunakan Bahasa Pemrograman C. MEKTEK, 13(1).

[7] Husni, N. L., Rasyad, S., Putra, M. S., Hasan, Y., \& Al Rasyid, J. (2020). Pengaplikasian Sensor Warna Pada Navigasi Line Tracking Robot Sampah Berbasis Mikrokontroler. Jurnal Ampere, 4(2), 297-306.

[8] Prasetyo, E. N. (2015). Prototype penyiram tanaman persemaian dengan sensor kelembaban tanah berbasis arduino (Doctoral dissertation, Universitas Muhammadiyah Surakarta).

[9] Wicaksono, C. B. (2019). Pengaruh Penggunaan FenderFramedrone Dan Beban Terhadap Konsumsi Arus Baterai (Doctoral dissertation, UNNES).

[10] B. Prabowo, "Pemodelan Sistem Kontrol Motor DC Dengan Temperatur Udara Sebagai Pemicu," INKOM J. Informatics, Control Syst. Comput., vol. 2, no. 1, pp. 39-43, 2008.

\section{BIODATA PENULIS}

Gusnita Parmitasari, lahir di Tangerang, 24 Agustus 1997. Sarjana Sains Terapan, di jurusan Teknik Elektro Program Studi DIV Teknik Elektro Indusri, Fakultas Teknik, Universitas Negeri Padang.

Dr. Sukardi, M.T, lahir di Semerap Kerinci Indonesi tanggal 10 Mei 1961, menempuh pendidikan di Kerinci sejak SD, SMP dan SMA, melanjutkan kuliah Sarjana (S1) di IKIP Padang Indonesia Jurusan Pendidikan Teknik Eleltro, Magister (S2) Teknik ELektro di Institut Teknologi Bandung, dan Program Doktor (S3) bidang Pendidikan Teknologi dan Kejuruan di Pascasarjana Universitas Negeri Yogyakarta. Saat ini bertugas sebagai Dosen dan menekukni riset bidang Pendidikan Teknologi dan Kejuruan Ketenagalistrikan. (TVET). 